\title{
Damascus Steel Revisited
}

\author{
J.D. VERHOEVEN ${ }^{1,},{ }^{1,5}$ A.H. PENDRAY, ${ }^{2}$ W.E. DAUKSCH, ${ }^{3}$ \\ and S.R. WAGSTAFF ${ }^{4}$ \\ 1.--Iowa State University, Ames, IA, USA. 2.-Williston, FL, USA. 3.-Nucor Corp, Charlotte, \\ NC, USA. 4.-Novelis Inc, Sierre, Switzerland. 5.-e-mail: jver@iastate.edu
}

\begin{abstract}
A review is given of the work we presented in the 1990s that successfully developed a technique for reproducing the surface patterns and internal microstructure of genuine Damascus steel blades. That work showed that a key factor in making these blades was the addition of quite small levels of carbideforming elements, notably V. Experiments are presented for blades made from slow- and fast-cooled ingots, and the results support our previous hypothesis that the internal banded microstructure results from microsegregation of $\mathrm{V}$ between dendrites during ingot solidification. A hypothetical model was presented for the mechanism causing the unique internal microstructure that gives rise to the surface pattern forming during the forging of the ingots from which the blades are made. This article attempts to explain the model more clearly and presents some literature data that offer support to the model. It also discusses an alternate model recently proposed by Foll.
\end{abstract}

\section{INTRODUCTION}

The Damascus steel swords found mainly in museums became famous because of their attractive surface patterns and their reputation originating in the crusades as being sharper and tougher than equivalent western swords. However, there was a mystery about how these swords were made because after around 1850 no one could make one. C.S. Smith, the chief metallurgist in the Manhattan project, brought the mystery of these blades to the attention of the metallurgy community in a book published in $1960 .^{1}$ He described what was known about the metallurgy of these swords and how they were made from small wootz steel ingots produced in India. It was known that the Damascus swords were forged from small hockey puck-sized highcarbon steel ingots made in India that are called wootz steel in the west. Smith presented micrographs of the internal microstructure of a blade showing alternating sheets of pearlitic steel and sheets of clustered small spheroidized carbide particles, $\mathrm{Fe}_{3} \mathrm{C}$. This laminated internal microstructure

A.H. Pendray: Deceased. produces the surface patterns on the swords after suitable etching. It is largely this unique surface pattern that has made the Damascus sword so famous. C.S. Smith and other participants at a 1985 conference on Damascus steel blades held at New York University ${ }^{2}$ agreed that the art of making these blades had been lost shortly after around the early nineteenth century.

In the 1990s we carried out an extensive set of experiments $^{3-5}$ in which bladesmith Alfred Pendray was able to produce knives that matched both the internal microstructure and external patterns of genuine Damascus steel swords. The experiments produced small hockey puck-sized ingots of steels having carbon compositions similar to those of genuine Damascus steel swords of around 1.5-1.7 wt.\% C. The aligned cluster sheets of small wellspheroidized carbide particles occurred on forging the ingots to blade shapes only if they contained a small amount, around $0.01 \%$, of carbide-forming elements, such as $\mathrm{V}$, Mo or $\mathrm{Cr}$, with $\mathrm{V}$ being most effective. The result was consistent with the fact that six genuine museum-quality Damascus swords were also found to contain $\mathrm{V}$ at low levels. ${ }^{3}$ Ingots forged to blade shapes of around 4-5-mm thicknesses produced microstructures and surface patterns closely matching those of museum-quality blades. 


\section{CONTROLLING THE SPACING OF THE CLUSTER SHEETS}

The blades consist of alternating sheets of clustered cementite particles and sheets of pearlite. The pearlite sheets can contain cementite particles. As the number of cementite particles in the pearlite sheets is reduced, the overall sheet sharpness is improved. When viewing the surface pattern of a Damascus blade from a comfortable distance, the boldness of the pattern perceived by the eye improves with sharper sheet formation for a given sheet spacing. Our experience examining both museum blades and blades made by Pendray have found that for a given sheet sharpness, the surface boldness is maximized with sheet spacings of around 40-100 microns. Our previous work ${ }^{3-5}$ hypothesized that the microstructure is formed by a type of banding due to the microsegregation of $\mathrm{V}$ between the dendrites during the solidification of the ingots. One would therefore expect the spacing to be set by either the primary or the secondary dendrite spacing in the ingot from which a blade is forged combined with the amount the ingot is reduced on forging. If controlled by the primary spacing, the resulting cluster sheet spacing would be larger than if it were controlled by a combination of secondary and primary spacings. Our initial studies used a phosphorus addition of around 0.1 wt.\% to match the composition measured on several well-patterned museum-quality blades. At this level of $P$, the ingots are hot short and very difficult to forge. We think this is why a 1722 report by Reaumur claimed that Parisian blacksmiths were unable to forge the small wootz cakes from India. ${ }^{1}$ The $\mathrm{P}$ forms a ternary eutectic called steadite, which becomes molten at the forging temperatures, thereby causing the embrittlement.

To overcome this problem we found that it was necessary to heat the ingots packed in an iron mill scale for around $10-12 \mathrm{~h}$ at $1100-1200^{\circ} \mathrm{C}$. This treatment produces a rim of nearly pure iron on the ingot and is termed a rim heat treatment. The iron rim adequately contains the molten steadite within the ingot so that it can be forged without cracking. Apparently, the Parisian bladesmiths had not learned the trick of the rim heat treatment. (Pendray was able to obtain an ancient partially forged bar of steel verified to be a Damascus bar from the Anwar Armory in India. Additional forging of this bar produced a typical surface Damascus pattern, and metallographic sections of the bar verified that it had been given a rim heat treatment ${ }^{6}$ ). Eliminating the $\mathrm{P}$ addition removed the hot shortness problem. The blades still produced excellent cluster sheet formation but, unfortunately, without the rim heat treatment the cluster sheet spacing was found to be significantly smaller. On such blades forged to thicknesses of $3-5 \mathrm{~mm}$, the spacings were running in the 20-30 micron range, and to easily see the surface pattern, it was necessary to use a magnifying glass. During the rim heat treatment, diffusion of $\mathrm{V}$ between the smaller distances would occur, which would be needed to homogenize the $\mathrm{V}$ compositions over secondary spacings. At the same time there would be some level of microsegregation of $\mathrm{V}$ between the primary spacings.

Experiments were recently carried out to produce blades made from ingots prepared as previously described $^{3,4}$ and cooled at slow and fast cooling rates. The fast rate was obtained by turning off the propane gas to the furnace that heated the enclosed crucibles. The slow rate was obtained by a slow reduction of propane gas. Figure 1 presents the time-temperature history of the ingots made at the two cooling rates. The temperature was measured at the bottom outside edge of the crucible with a platinum thermocouple (type B). Experiments with thermocouples placed both below the bottom of the crucible and in a ceramic protection tube inside the crucible at the bottom of the melt showed that outside temperatures ran $33 \pm 4^{\circ} \mathrm{C}$ higher and $18 \pm 4^{\circ} \mathrm{C}$ lower than the inside melt temperature on heating versus cooling, respectively. Chemical analysis of ingot 8115 is presented in Table I. The iron carbon phase diagram ${ }^{7}$ gives a liquidus temperature of $1423^{\circ} \mathrm{C}$ for $1.57 \% \mathrm{C}$. Hence, the melt was heated to a maximum temperature of $1468^{\circ} \mathrm{C}$ and held above the liquidus of $1423^{\circ} \mathrm{C}(\sim 1390$ on heat up and $\sim 1441$ on cool down on the plot) for $\sim 65$ min. It is interesting to point out that when crucible steel was being produced in the late nineteenth century, to sufficiently kill the steel and avoid porosity in the ingots, they simply held the melt until it stopped bubbling. ${ }^{8,9}$ They had to hold the melt temperature above the freezing temperature for 30-40 min before gas evolution stopped. The authors do not specify what actual temperature was used. It must be that times of at least 30-40 min are required for the $[\mathrm{O}]+[\mathrm{Fe}] \leftrightarrow \mathrm{CO}$ equilibrium to be achieved adequately to avoid cavity porosity on their cooled ingots. Apparently the 30-min hold of ingot 8115 adequately killed the steel so that cavity porosity did not occur at the cooling rate of this ingot. The cooling rate given by the slope of the curve during subsequent dendrite growth was around $4.3^{\circ} \mathrm{C} / \mathrm{min}$.

Such was not the case at slower cooling rates. Several attempts were made to cool ingots at slower rates, but large cavity porosity was found in the ingots, which made it nearly impossible to forge them to blade shapes. It seemed most likely that this porosity was due to evolution of $\mathrm{CO}$ gas on cooling at the slow rates. Cavity porosity in the slow-cooled ingot 7315 was avoided by adding a borosilicate glass ampoule filled with $1.4 \mathrm{~g}$ of $\mathrm{Al}$ and $1.4 \mathrm{~g}$ of a chloride-based fluxing salt. The glass ampoule plus the fluxing agent prevented the $\mathrm{Al}$ from oxidizing before it could dissolve into the melt and thereby prevented $\mathrm{CO}$ evolution just as it does in aluminum-killed steels. Table I shows that the 


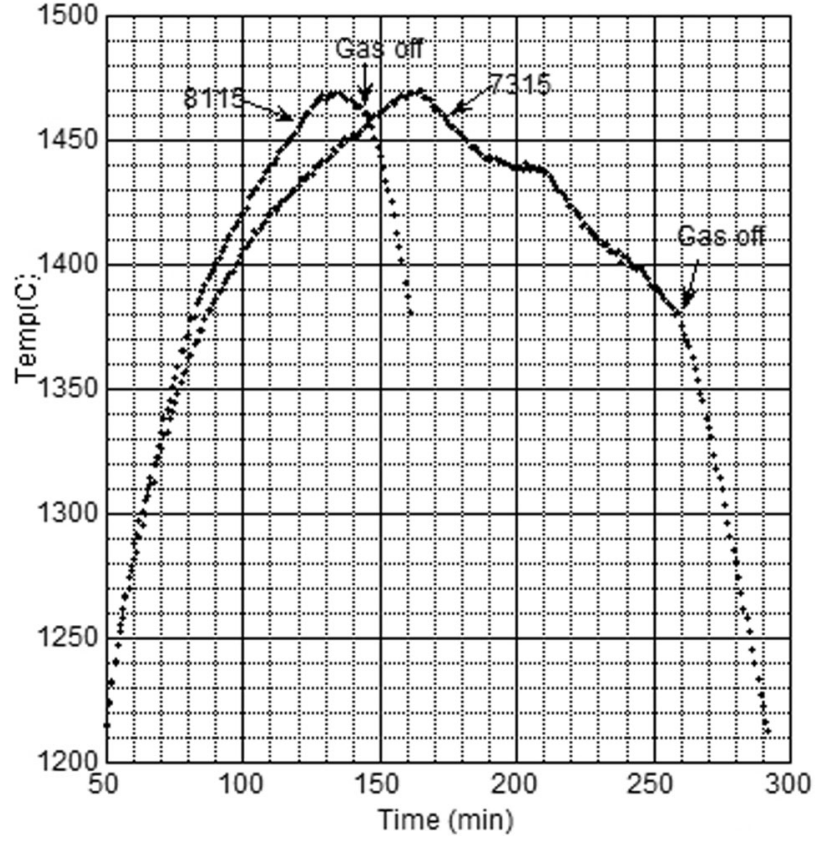

Fig. 1. Temperature versus time for ingots 8115 and 7315 .

Table I. Chemical analysis of fabricated blades

\begin{tabular}{lll}
\hline Element & $\mathbf{7 3 1 5}$ & $\mathbf{8 1 1 5}$ \\
$\mathrm{C}$ & 1.57 & 1.57 \\
$\mathrm{Mn}$ & 0 & 0 \\
$\mathrm{~V}$ & 0.061 & 0.047 \\
$\mathrm{Mo}$ & 0.01 & 0.01 \\
$\mathrm{Cr}$ & 0.02 & 0.02 \\
$\mathrm{Zr}$ & 0.002 & 0 \\
$\mathrm{Nb}$ & 0.009 & 0.002 \\
$\mathrm{Ti}$ & 0.003 & 0.001 \\
$\mathrm{~S}$ & 0.006 & 0.008 \\
$\mathrm{Sn}$ & 0.009 & 0.003 \\
$\mathrm{P}$ & 0.02 & 0.025 \\
$\mathrm{Al}$ & 0.014 & 0.008 \\
$\mathrm{~B}$ & 0.0008 & 0.0003 \\
$\mathrm{Cu}$ & 0.01 & 0.01 \\
$\mathrm{Ca}$ & 0.0002 & 0.0007 \\
$\mathrm{Ni}$ & 0.02 & 0.02 \\
$\mathrm{~Pb}$ & 0.0082 & 0.0007 \\
$\mathrm{~N}$ & $<0.016$ & $<0.016$ \\
\hline
\end{tabular}

carbon composition of ingot 7315 is the same as that of ingot 8115; hence, it has the same liquidus temperature of $1423^{\circ} \mathrm{C}$. It was heated to a maximum temperature of $1468^{\circ} \mathrm{C}$, held above the liquidus for 108 min and subsequently cooled through the dendrite growth range at an average rate of around $1{ }^{\circ} \mathrm{C} /$ min. There was no cavity porosity in this slowcooled ingot.

Both ingots were given a rim heat treatment of $16 \mathrm{~h}$ at $1040^{\circ} \mathrm{C}$. The ingots were $90 \mathrm{~mm}$ diameter by $43 \mathrm{~mm}$ height. Both ingots were forged to a blade shape with dimensions of $43 \mathrm{~mm}$ wide by a bit under $8 \mathrm{~mm}$ thick. A total of 36 forging cycles were

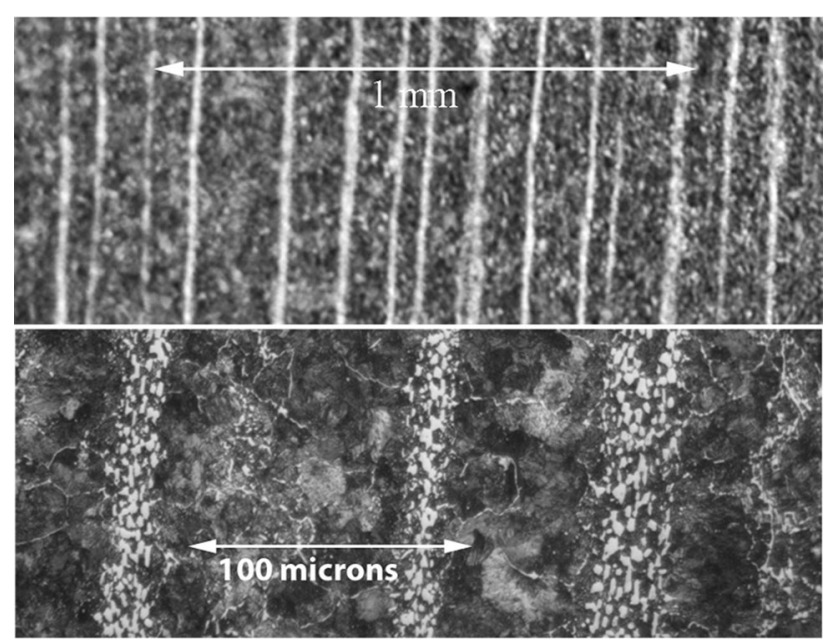

Fig. 2. Longitudinal section of a blade from ingot 7315.

employed with the first 7 carried out over a temperature range of $\sim 1030^{\circ} \mathrm{C}$ to $700^{\circ} \mathrm{C}$ and the remainder over the range of $\sim 925^{\circ} \mathrm{C}$ to $700^{\circ} \mathrm{C}$ followed by three thermal cycles between $950^{\circ} \mathrm{C}$ and $700^{\circ} \mathrm{C}$. The blades were forged to a thickness of $7.75 \pm 0.05 \mathrm{~mm}$, and both displayed excellent cluster sheet alignment. As expected, the slower cooled ingots produced blades with a larger average cluster sheet spacing, $93 \mu \mathrm{m}$ versus $71 \mu \mathrm{m}$ for ingot 8115 . These results present additional evidence that the formation of the aligned cluster sheet spacing is a result of the microsegregation of the carbide-forming element $\mathrm{V}$ between the dendrites during solidification of the ingot. Blade 8115 was forged further to a thickness similar to a knife blade or a sword, $2.8 \mathrm{~mm}$, and the cluster sheet spacing dropped to 45 microns.

Figure 2 presents a micrograph of blade 7315 at $7.8 \mathrm{~mm}$ thickness, and the enlargement illustrates the nature of the clustered arrays of cementite particles in the cluster sheets as well as the pearlite sheets between the cluster sheets. The amount of cementite in the pearlite sheets has been reduced adequately to produce a bold surface pattern.

\section{DISCUSSION OF PROPOSED MODEL FOR PATTERN FORMATION}

As discussed in the supplementary material, the dendritic solidification of steel results in the formation of sheets of dendrites separated by interdendritic sheets. Previous work presented a hypothetical model ${ }^{4,5}$ for the mechanism of the formation of the laminated internal microstructure that forms on forging. The model will be more fully explained here and some literature data that offer support to the model presented. An alternate model that has come to our attention will also be discussed.

In a previous study, ${ }^{10}$ metallographic examinations of the evolution of the microstructure of forged ingots at various stages of the forging 

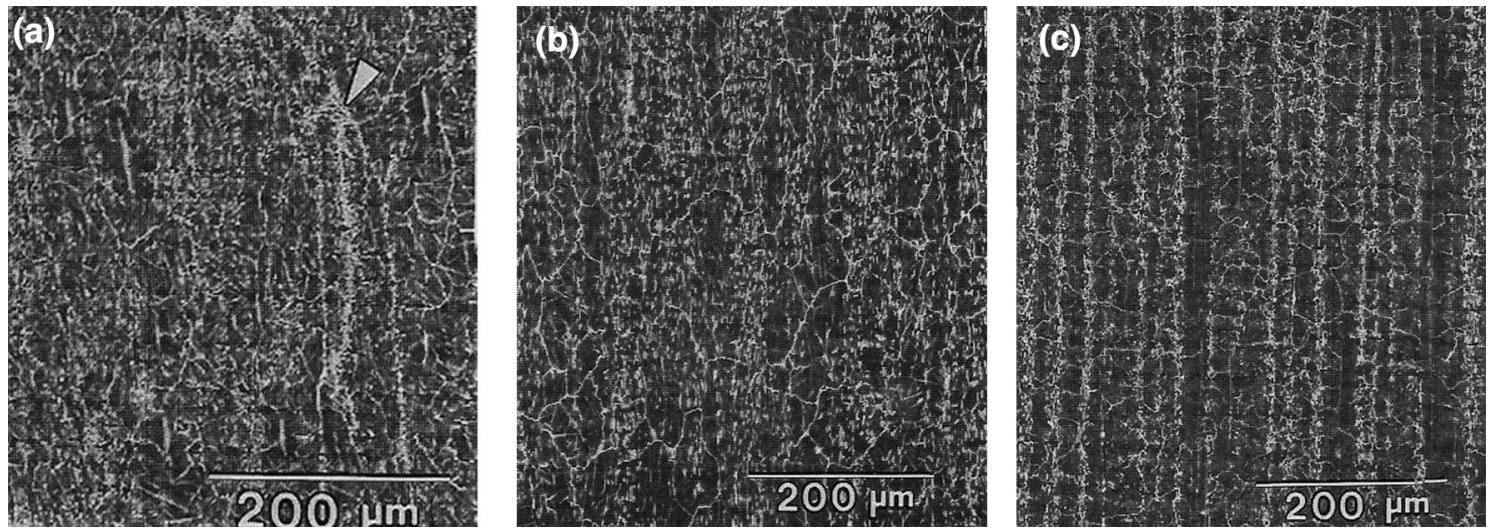

Fig. 3. Longitudinal sections of a blade after forging to sizes of (a) $36 \times 18 \mathrm{~mm}, 27$ cycles; (b) $36 \times 14 \mathrm{~mm}, 34$ cycles; and (c) $45 \times 5 \mathrm{~mm}, 70$ cycles.

sequence from ingot shape to thin blade shape have been evaluated, and micrographs are shown in Fig. 3. It was found that the large blocky cementite carbides formed in the original ingot were quickly replaced by small spheroidized cementite particles after initial forging at high temperatures. We think the formation of the small spheroidized carbide particles was enhanced by the forging flow because as the temperature drops below the $A_{\mathrm{cm}}$ temperature, sheet-like carbides formed on austenite grain boundaries would break up because of the forging flow and quickly spheroidize at the high temperatures. The arrangement of the carbide particles in the forged bars was found to be random after the $90-\mathrm{mm}$-diameter by 43-mm-high ingot had been forged into a blade shape with a $36-\mathrm{mm}$-wide by $18-\mathrm{mm}$ thick cross section. This took 27 forging cycles. The carbide particles appear to have nucleated on prior austenite grain boundaries as demonstrated by the triple junction shown at the arrowhead in Fig. $3 \mathrm{a}$ as well as on prior austenite grain boundaries. The carbide distribution at this stage of forging appears fairly random. On additional forging, it was found that the cementite carbide particles slowly began to arrange themselves into the cluster sheet geometry with the density of clustering and the alignment of the sheets improving as the number of forging cycles increased. After 70 forging cycles when the blade thickness was reduced to $5 \mathrm{~mm}$, Fig. 3c, the cluster sheet geometry became well formed. So, the critical question is what is causing the carbides to cluster together into the aligned cluster sheets in the later stages of forging.

\section{DISCUSSION OF THE PATTERN FORMA- TION MODEL AND SUPPORTING LITERA- TURE DATA}

The proposed model requires a selective coarsening during the multiple forging cycles of the cementite particles in the interdendritic sheets where the
$\mathrm{V}$ has been concentrated. In pure iron/carbon steels, cementite has the chemical formula $\mathrm{Fe}_{3} \mathrm{C}$. When alloying elements dissolve into the cementite, it is customary to designate the chemical formula as $\mathrm{M}_{3} \mathrm{C}$ where $\mathrm{M}=\mathrm{Fe}+\mathrm{X}$, with $\mathrm{X}$ being primarily $\mathrm{V}$ in this case. During the heat-up stage of a forging cycle, the cementite particles will begin to dissolve into the neighboring austenite. If the highest temperature does not exceed the $A_{\text {c-cm }}$ temperature, some of the cementite particles will remain at the highest temperature and will then grow in size as the temperature falls. If the alloying element in the $\mathrm{M}_{3} \mathrm{C}$ carbide reduces the mobility of the carbide/ austenite interface, then the $\mathrm{M}_{3} \mathrm{C}$ carbides in the interdendritic sheets will become larger than the $\mathrm{Fe}_{3} \mathrm{C}$ carbides in the dendritic sheets as the temperature rises. There are three possibilities:

Case 1 At the highest forging temperature, both some $\mathrm{Fe}_{3} \mathrm{C}$ and some $\mathrm{M}_{3} \mathrm{C}$ particles survive. But the $\mathrm{M}_{3} \mathrm{C}$ particles are larger and have a higher number density.

Case 2 At the highest forging temperature, all of the $\mathrm{Fe}_{3} \mathrm{C}$ particles have been dissolved but some of the $\mathrm{M}_{3} \mathrm{C}$ particles have survived.

Case 3 At the highest forging temperature, all of the cementite particles have dissolved.

On cool down, the cementite particles will grow in size. In case 1 , it might be possible for the remaining $\mathrm{Fe}_{3} \mathrm{C}$ particles, which grow faster than the $\mathrm{M}_{3} \mathrm{C}$ particles, to increase their size and match that of the larger but slower growing $\mathrm{M}_{3} \mathrm{C}$ particles. Then, if enough of the $\mathrm{Fe}_{3} \mathrm{C}$ particles nucleate in the dendritic sheets to match the number density in the interdendritic sheets, no enhanced coarsening occurs in the interdendritic sheets. But if few or no additional $\mathrm{Fe}_{3} \mathrm{C}$ carbide particles nucleate in the dendritic sheets on cool down, one would find larger 
carbides in the interdendritic sheets after each cool down step of the forging, which eventually would cause the selective coarsening of carbides in the interdendritic sheets as the number of forging cycles increases.

Nucleation of new cementite particles is a relatively difficult process requiring some supercooling. If the carbon being forced out of the austenite as the temperature drops can deposit onto existing carbides it will do so rather than nucleating additional carbides. The $\mathrm{M}_{3} \mathrm{C}$ carbides in the interdendritic sheets will be close by the dendritic sheets, and it is postulated that the carbon will simply diffuse to the $\mathrm{M}_{3} \mathrm{C}$ carbides rather than nucleating new $\mathrm{Fe}_{3} \mathrm{C}$ carbides in the dendritic sheets. The net effect will be the selective coarsening of cementite particles in the interdendritic sheets that is observed in experiments such as shown in Fig. 3.

Case 2 would produce the selective coarsening even more quickly during the forging cycles because the number density of $\mathrm{Fe}_{3} \mathrm{C}$ carbides in the dendritic sheet region would begin at zero at the start of cool down. Case 3 will be considered later.

If the hypothesized mechanism for coarsening is correct, it requires that:

Requirement 1 Cementite carbides in interdendritic sheets contain a significant amount of $\mathrm{V}$ dissolved into them, while cementite carbides in the dendritic sheets ae $\mathrm{V}$ free.

Requirement 2 The dissolved $\mathrm{V}$ must reduce the mobility of the austenite/cementite interface during growth or shrinkage processes.

Requirement 1 As explained in the supplementary material, an electron microprobe study ${ }^{5}$ found that carbides formed in the interdendritic sheets contained significant amounts of dissolved V, while those in dendritic sheets were $\mathrm{V}$ free.

Requirement 2 As shown in the supplementary material data on the effect of the carbide forming elements, Mo, Cr and Mn on hardness loss during tempering [S3] offer strong experimental support that dissolved carbide particles significantly reduce the mobility of cementite/iron interfaces.

\section{AN ALTERNATE POSSIBLE MECHANISM FOR CLUSTER SHEET FORMATION DURING FORGING}

H. Foll ${ }^{11}$ has hypothesized an alternate mechanism for cluster sheet formation during forging that could occur for case 3 discussed above. The carbideforming elements form native carbides such as VC for $\mathrm{V}$. These native carbides form at higher temperatures than $\mathrm{Fe}_{3} \mathrm{C}$ and would be stable at the highest forging temperatures; hence, they could act as nucleating agents for cementite formation in the cooling step of forging. This hypothesis is discussed in detail in the supplementary section, and several reasons are presented for why it is unlikely. One of the main reasons is that although native carbides were found in the interdendritic regions of $\mathrm{V}$ and $\mathrm{Mo}$ blades in the study of Ref. ${ }^{5}$, no native carbides were found in the $\mathrm{Cr}$ and $\mathrm{Mn}$ steels, which showed cluster sheet formation.

\section{CONCLUSION}

The pattern on genuine Damascus steel swords and blades is produced by the formation of aligned sheets of clustered cementite particles separated by sheets of pearlite. Experiments are presented on blades made from ingots solidified at slow and fast cooling rates, and the results are consistent with our previous hypothesis that this microstructure is produced by a type of banding caused by microsegregation of $\mathrm{V}$ between the dendrites formed during solidification. Some previous work ${ }^{10}$ is reviewed, which show that the formation of the carbide cluster sheets requires the presence of very low levels of carbide-forming elements and only occurs after many forging cycles and that the alignment and sharpness of the cluster sheets improve with the number of forging cycles. The hypothetical model for the mechanism of this effect involving selective coarsening of the cementite carbides in interdendritic sheets presented by the authors ${ }^{4},{ }^{5}$ has been reviewed in some detail. An alternate model suggested by $\mathrm{H}$. Foll involving nucleation of cementite on primary carbide has been shown to be possible but unlikely. In addition, literature data on the effect of carbide-forming elements on reducing hardness loss of steels on tempering after quenching is shown to offer support for the model.

\section{ACKNOWLEDGEMENTS}

The chemical analyses presented in Table I were carried out by Mark Schmidt at Nucor Steel Mill, Darlington, SC. The metallography was done with equipment provided by Iowa State University, and the glass ampule was prepared with equipment at MIT.

\section{ELECTRONIC SUPPLEMENTARY MATERIAL}

The online version of this article (https://doi.org/ 10.1007/s11837-018-2915-z) contains supplementary material, which is available to authorized users.

\section{REFERENCES}

1. C.S. Smith, A History of Metallography, Chapters 3 and 4 (MIT Press, Cambridge MA, 1960 and 1988).

2. D.W. Ecker and G.N. Pant, The Damascus Blade: Legends and Realities. in Proceedings of Symposium On the Bladesmiths Art (New York University, New York, NY 1985).

3. J.D. Verhoeven, A.H. Pendray, and W.E. Dauksch, J. Met. 50,58 (1998).

4. J.D. Verhoeven, A.H. Pendray, and E.D. Gibson, Mat. Char. 37, 9 (1996).

5. J.D. Verhoeven, A.H. Pendray, and W.E. Dauksch, Trans. ISS Iron Steelmak. 25, 65 (1998). 
6. J.D. Verhoeven, A.H. Pendray, and W.E. Dauksch, J. Met. 56, 17 (2004).

7. Metals Handbook, 8th edn. vol. 8, (American Society for Metals, 1973), p. 275.

8. O.M. Becker, High Speed Steels (New York: McGraw-Hill, 1910), p. 58
9. Making Shaping and Treating of Steels, 7th edn. (U.S. Steel Co., 1957), p. 264.

10. J.D. Verhoeven and A.H. Pendray, Mat. Char. 30, 175 (1993).

11. H. Foll, 11.5 Wootz Swords (2017), https://www.tf. uni-kiel.de/matwis/amat/iss/kap_b/backbone/rb_5_1.html\#_ dum_2. 